\title{
DE REQUESTEN VAN PATER STÖPPEL EN PREFECT WENNEKERS IN 1817 EN 1819
}

DOOR

\section{fr. M. F. Abbenhuis}

Voor onze kennis van het leven der gedoopte en niet-gedoopte slaven in de tijd van de zogenaamde voorbereiding der emancipatie zijn de kerkelijke bronnen van veel meer belang dan de gouvernementele. Het is daarom wel merkwaardig, dat bij de meeste Surinaamse geschiedbeschrijvingen geen gebruik werd gemaakt van gegevens uit de katholieke werken van Bossers, KroONENBURG, Dahlaus, Govers, en anderen.

Als de oorzaak hiervan gelegen zou zijn in de mening, dat in de Surinaamse geschiedenis de katholieke invloed gering geweest is, dan moge dit artikel aantonen hoe ver misgetast werd bij, b.v. de volgende beweringen:

„In de laatste jaren hebben de Roomsch Catholijken zich de godsdienstige belangen der slaven aangetrokken." (WoLBERS, 1861, p. 767)

,Door sommige priesters wordt geen nauw toezicht op de zedelijkheid der aan hun zorg toevertrouwden gehouden." (Wolbers, 1861, p. 767)

„In den slaventijd ... was het ... den zendelingen verboden [de slaven] kerkelijk te trouwen." (Encycl. Ned. W. Indië, 1914, p. 180)

„Ook de R.K. Kerk begon onder de slaven te werken.... vanaf 1848 groeide het aantal leden." (STEINBERG, p. 170, bij VAN LIER, 1949, p. 290)

„,Sinds 1850 hadden de zendelingen het mogelijk gemaakt [voor de slaven] om een zogenaamd verbond te sluiten." (VAN LIER, 1949 , p. 290 )

Het request van P. Wennekers, prefect van de Surinaamse Missie, en pastoor van Paramaribo, te samen met dat van J. STÖPPEL O.F.M., pastoor op Curaçao, bewijst: le dat de R.K. Missie zich het lot der slaven eerder dan 1850, en in zekere zin 
intenser dan anderen heeft aangetrokken; 2e dat de actie van deze beide personen grote gevolgen heeft gehad, ook voor het respectabel werk van andere gemeenten; 3e dat het katholiek kerkelijk huwelijk voor slaven wèl mogelijk was, en ook veel vroeger dan 1850; 4e dat er bezwaarlijk sprake kan zijn van slecht toezicht of verwaarlozing van morele tucht van de zijde van het hoofdbestuur van de Kerk in Suriname en Nederland.

De requesten, met heel hun nasleep van officiële rapporten, protesten en besluiten, mogen ter staving van deze vier beweringen voor zich zelf spreken.

De Duitse Franciskaanse pater J. STöPpel kwam in Juli of Augustus 1816 op Curaçao aan. Als man van 47 jaar vormde hij zich spoedig een zelfstandig oordeel omtrent de geestelijke toestand der slaven en de middelen ter verbetering. Geen gehoor vindend bij zijn pastor primarius, de 70-jarige pater Pirovano O.F.M., die al 30 jaren op Curaçao was, en evenmin bij de gouverneur (zie Dahlaus, p. 29, 39, 402 en 412), wendde hij zich door middel van zijn vriend Tomas (Bossers, p. 127; Chronica p. 100), pastoor van de Franse kerk in Den Haag, tot zijn hogere overste J. Cramer, Aartspriester van Holland, Zeeland en West Friesland ${ }^{1}$ ). (v. D. Loos, p. 245; Kath. Enc.)

Deze Cramer was een zeer invloedrijk persoon, man van hoge cultuur, aalmoezenier aan het hof van koning LoDEwIJK NAPOLEON en lid van de commissie van advies voor de kerkelijke organisatie, protonotarius apostolicus, enz. Hij nam de zaak der slaven hoog op, interesseerde zich ook bijzonder voor de Surinaamse toestanden, die STöPPEL beschreef - „naar horen zeggen van iemand die er anderhalf jaar gewoond heeft." CRAMER nam vooral de aanmaning ter harte om spoedig priesters naar Suriname te sturen. Hij stelde, aan de hand van de brief die pastoor Tomas hem schreef, het request op (Dahlaus, p. 397), en ofschoon Tomas had voorgesteld om het zelf te mogen aanbieden aan Gouban, directeur van het op te richten ,"Bureau van de Catholyke Eeredienst" in Den Haag (Bossers, p. 100), onder-

1) De Katholieke Kerk van Nederland was in die dagen missiegebied, genaamd de Hollardsche Zending, welke werd bestuurd door Aartspriesters onder de Nuntius. De Aartspriester van Holland, zetelend te Amsterdam, was tevens verzorger der geestelijke en tijdelijke belangen der „Parochie van Paramaribo”, zoals de Surinaamse Katholieke Missie genoemd werd. Door hem werden de priesters voor Suriname beroepen en uitgezonden, alsook die van Curaçao. 
tekende toch CRAMER het request (DAHLAUs, p. 399) en bood het op 13 October 1817 den koning aan. - Eerder, in Augustus al, zond hij een dringende oproep voor Suriname aan alle geestelijken van zijn jurisdictie.

Het initiatief van StöPpel leidde niet alleen tot officiële Curaçaose protesten, rapporten en besluiten, maar had ook tot gelukkig gevolg de feitelijke bevestiging van de Surinaamse Missie, een Surinaams request voor de slaven, Surinaamse rapporten en ten slotte de opbloei der Surinaamse slavenkerk - allereerst die der Evangelische Broedergemeente en daarnaast die der R.K. Kerk.

Op Curaçao werd het request van STÖPPEL volkomen verworpen : gedesavoueerd door zijn pastoor PIROVANO; veroordeeld door de Raad van Policie in een vernietigend rapport aan de gouverneur, en door deze aan de regering in Nederland in een korte missieve, waarin ook de persoon van de inmiddels overleden StÖPPEL veroordeeld werd (DAHLAUS, p. 401, 405 en 411).

STÖPPEL overleed te Curaçao op 10 October 1818. - DaHLAus (p. 31 en 416) toont aan dat hij feitelijk gelijk had, en niet Pirovano, hetgeen blijkt uit gouvernementele besluiten en vooral ook uit de bemoeiingen van zijn opvolger Mgr. NiEwINDT, die tot zijn dood, in 1860, streed voor sociale en religieuze verbeteringen ten gunste van de slaven.

Hoewel, sinds 1828, voor de slaven van Suriname en Curaçao dezelfde officiële bepalingen golden, waren de gevolgen van StöPPEL's request voor Suriname minder ongunstig dan voor Curaçao.

Twee Priesters waren op 21 November 1817 te Paramaribo aangekomen: de seculieren P. WENNEkERS en L. VAN DER HORST, jonge mannen van 28 en 29 jaren; de eerste als Prefect en pastoor, de tweede als kapelaan.

In het voorjaar van 1818 sprak WENNEKERS - volgens een bericht in de Godsdienstvriend ( $I$, p. 64) - reeds in een brief aan Cramer de wens uit ,dat de eigenaren bewogen wierden tot medewerking, vooral in de kwestie van het slavenhuwelijk." En in 1819 vermeldt hetzelfde tijdschrift $(2$, p. 126) zijn actie voor een request, dat zowel het huwelijk als de separate verkoop van moeders en kinderen zal behandelen. In een vurige opwekking stelt de redacteur - de bekende emancipator van Nederlandse Katholieken LE SAGE TEN BROEK - het recht van request voor, en hij spoort tevens aan tot steun aan het Liefdefonds van WENNEKERS, tot vrijkoop van Surinaamse slaven. LE SAGE herinnert 
daarbij aan de actie van StöPPEL, wiens woord dus als een goed zaad een nieuwe plant opleverde: emanciperende verzameling van Nederlandse Katholieken op het terrein der Missieactie.

Voor het vertrek van WENNEKERS had CRAMER hem ongetwijfeld ingelicht over de Surinaamse toestanden. Het is dan ook geen wonder dat WENNEKERS - vertrouwende op de goedwillendheid van de koning en van de gouverneur - reeds in Juli 1819 zijn request aanbood (Bossers, p. 129; Chronica p. 101).

BossErs was niet op de hoogte van het verloop en de wijze van aanbieding; verondersteld mag worden dat de officiële weg bewandeld werd, zoals bij STÖPPEL, nl. ondertekening en aanbieding door CRAMER. Voor de tekst vermeldt hij geen bron; mogelijk heeft Bossers een copie uit het archief van het bisdom Haarlem gebruikt. In het archief van het Vicariaat van Suriname is geen handschrift van ontwerp of definitieve tekst van het request voorhanden. Het is niet onmogelijk dat WENNEKERS' origineel wordt teruggevonden in het huisarchief van H. M. de Koningin, gelijk DAHLAUS vermeldt voor dat van STÖPPEL.

Volgens de Surinaamse berichten uit de brief van StöPpEL aan Tomas, Juni 1817, vormen doop, huwelijk en separate verkoop de hoofdpunten van WenNekERs' verzoek. Hij spreekt echter niet, zoals STÖPPEL, over de verwaarlozing van bejaarde, afgewerkte en stervende slaven in Suriname, noch over de noodzakelijkheid van een nieuw slavenreglement voor Suriname en Curaçao. Hij schetst de toestand aldus: Bij Joodse en andere eigenaren ${ }^{1}$ ) wordt de vrije missionering belet wat betreft het dopen van volwassenen en kinderen, het aangaan van huwelijken, het onder-

1) Wennekers legde de nadruk op het verzet der eigenaren. De meesten woonden in Nederland, en zeer veel plantages behoorden niet aan particulieren, maar aan Fondsen, Erven, Boedels of Huizen. Tekenend voor de toestand is de houding van de meest vooraanstaande katholiek in WeNNEKERS' jaren 1817-1824, de heer E. v. D. BERGH. Hij was lid van het Hof van Politie, bekleedde vele officiële ambten, was leidend lid van de kerkraad en fervent katholiek. Maar hij was tevens GrootAdministrateur en beheerde voor Nederlandse eigenaren rond 20 plantages. Persoonlijk was hij - indien hij eigenaar zou zijn - vóór volstrekte, totale christianisering van de slaven, en vóór gouvernementele regeling daarvan. In de practijk vreesde hij echter dat zijn bedrijfssuperieuren hem de slechte gang van zaken zouden verwijten bij toelating van priesters, te meer omdat zijns inziens het geestelijk werk maar half uitvoerbaar zou zijn en dus meer schadelijk dan nuttig; terwijl hij terugschrok voor de herhaalde bemiddeling tussen priesters en plantagedirecteuren en opzichters. Het gevolg hiervan was dat hij de geestelijken de toegang weigerde tot al zijn beheerde plantages, geen katholieke directeuren en opzichters aannam en ook geen plantages wilde beheren van particuliere katholieke eigenaren in Nederland. 
wijzen vooral van kinderen, het toedienen van de H.H. Sacramenten aan zieken en afgedwaalden. Hij wijst op de verplichte zending en het gebod des Heren ten aanzien van de doop, de vrije aanneming van de godsdienst, die internationaal, en ook door de Nederlandse Grondwet gewaarborgd is; op het nadelig gevolg van belemmering van vormend onderwijs, zowel voor de slaven als voor het prestige van het Christendom.

Tot zover is het request dus een pleidooi voor godsdienstige emancipatie. WENNEKERS begreep dat een actie voor directe sociale emancipatie niet op zijn weg lag, en hij dus de vrijheid van het geestelijk leven der slaven slechts kon schaden bij afwijzing.

WENNEKERS wist uit eigen ervaring hoe sterk de vooroordelen waren van personen in de kringen van regering, gouvernement en slaveneigenaren. Van christianisering werd slechts wanorde, verzet, arbeidsverlies, onbetrouwbaarheid en slechte zeden verwacht. Het is dus begrijpelijk, dat het request daarna overgaat in een pleidooi voor het Evangelie: dat overeenkomstig de overtuiging van Zijne Majesteit altijd goede orde ondergeschiktheid, werkzaamheid, eerlijkheid, oprechtheid en goede zeden zou uitwerken, terwijl de slechte verwachtingen veeleer aan verwaarlozing van onderwijs, hartstochten en afgoderij te wijten zijn, zodat juist mede omwille van het belang van de kolonie en van de eigenaren een gunstige beschikking van $Z_{\text {ijne Majesteit verwacht }}$ wordt. Niet de minste schade zal door de doop worden toegebracht. Het onderwijs zal buiten arbeidstijd gegeven worden en bij voorkeur aan kinderen die nog niet tot arbeiden geschikt zijn. Het huwelijk is bij ondervinding voordelig.

Dus vraagt hij: le minstens het kerkelijk huwelijk; 2e een verbod, zo niet van separate verkoop dan toch van zodanige scheiding, dat zij, die met medeweten van de eigenaar kerkelijk getrouwd zijn, niet meer tot elkaar zouden kunnen komen; 3e het dopen van Creolen (d.i. van in het land geboren slavenkinderen) en van bejaarden.

En in het slot wijst hij dan nogmaals op het tijdelijk en ook eeuwig voordeel voor de planters, op de gebedsvoorspraak van de nieuwe Christenen, en op het goedgunstig advies van de gouverneur, zodat hij zich verzekerd acht, dat ook Zijne Majesteit een gunstige beschikking wenselijk oordeelt.

Bossers heeft geen kennis gehad van de ambtelijke gevolgen van dit request. Eerst in 1924 publiceerde Dahlaus (p. 400) de titels van missieven en rapporten, terwijl pater C. VeRMeulen C.ss.R. mij de teksten 
toezond van de Surinaamse commissie en van de gouverneur van Suriname, welke bij DaHLaus wel vermeld maar niet gepubliceerd waren. Volgens DAHLAus werden beide requesten in ieder land eerst behandeld door een commissie uit de Raad van Policie, daarna in een rapport van beider gouverneurs, en daarna gezamenlijk in Nederland door de Commissie voor de Zaken der Protestantse Kerken in Nederl. Oost en West Indië te 's-Gravenhage. Zowel in de West als in Nederland waren de rapporten der Commissies antwoorden op vragen door de Minister gesteld.

De rapporten van Curaçao blijven hier buiten bespreking.

In Suriname legde de gouverneur de vragen van de Minister van Onderwijs, Nationale Nijverheid en Kunsten voor aan de leden van het Hof van Policie: J. Bruyning, H. C. Perret Gentil en Dominee H. Uden Masman. Deze antwoordden op 31 Januari 1820 in een stuk van 7 bladzijden druks. Zij verwierpen het burgerlijk huwelijk omdat: le de slaaf geen burgerlijk persoon is; 2e de slaven daardoor onafhankelijk zouden worden, daar hun dan de vrijheid verleend werd contracten te sluiten of te verbreken (m.a.w. het verlenen van het recht op een burgerlijk huwelijk zou een volledige emancipatie betekenen); 3e zij zich daardoor boven hun stand zouden verheffen, handelend in strijd met de orde in een slavenmaatschappij; 4e zij zeer veranderlijk en wispelturig zijn in de voldoening hunner geslachtsdrift, waardoor in plaats van standvastigheid veeleer gedurige ontbinding en verwarring ontstaan zou; $5 \mathrm{e}$ het gezag van de meester er onder zou lijden; 6e het een vraag is hoe een slaaf voor een gezin en voor de opvoeding van kinderen zou kunnen zorgen; 7e het eveneens een vraag is hoe en met welke formaliteiten het huwelijk gesanctioneerd zou moeten worden, en om welke redenen gedissolveerd.

Het grote verschil tussen het request van StöPPEL en dat van WENNEKERS is, dat de eerste persoon op het gratis en gemakkelijk te sluiten burgerlijk en kerkelijk huwelijk aandrong, terwijl de tweede alleen om het kerkelijk huwelijk vroeg.

De Surinaamse Commissie verklaarde nog ernstiger bezwaren te hebben tegen het kerkelijk dan tegen het burgerlijk huwelijk: De slaven zullen nooit af te brengen zijn van hun bijgelovige en afgodische denkbeelden; van het Opperwezen en zijn dienst heeft het gros slechts een zeer duister en verward begrip; van het heilzaam en verbindend gezag van het huwelijk hebben zij geen denkbeeld - hoe zullen zij een plicht betrachten welke zij niet kennen? - en bovendien is het kerkelijk huwelijk moeilijk uit te voeren en onraadzaam bij de tegenwoordige toestand van de kolonie. Wat de separate verkoop van man en vrouw met hun nog niet voor de arbeid geschikte kinderen betreft, is de commissie van oordeel dat er niets te wensen valt ten aanzien van de verkoop van moeders met kinderen, want dezen mogen alleen voor de vrijdom separaat verkocht worden. Maar een verbod om man en vrouw geschei- 
den te verkopen, zou tot nadeel van de meesters strekken, terwijl het beoogde doel van huwelijkseenheid toch niet bereikt zou worden, omdat de Negers hun verbintenis doen afhangen van hun drift, die zo wispelturig is, dat zij doorgaans twee, drie, ja soms meerdere vrouwen hebben. De weinige voorbeelden van een goed huwelijk onder hen kunnen niet tot regel strekken; daarom kunnen de belangen van de meesters ook niet opgeofferd worden aan de verplichting om dergelijke los verbonden mannen en vrouwen te samen te kopen of te verkopen.

Hierna gaan de rapporteurs over tot een ongevraagd advies aan de gouverneur persoonlijk. (1) Zij dringen aan op gouvernementele aanmoediging tot het burgerlijk huwelijk onder ,,vrije lieden en zogenaamde Couleurlingen",wijzend op het belang ervan voor de matschappij, en voor de vele verlaten kinderen; wijzend ook op het slechte voorbeeld door de ouders aan hun kinderen gegeven - vervolgens ook wijzend op het komend gevaar van een hogere stand van kleurlingen, levend zonder huwelijksband. (2) De Commissie stelt een huns inziens meer practische bevordering van beschaving en zedelijkheid onder slaven voor, nl. door vestiging van Europese eigenaars in de kolonie, ter beter toezicht op onmatige, ontuchtige, slordige of wrede plantagedirecteuren; ook zal een zedelijk voorbeeld van blanken en vrije kleurlingen, meer strekken tot verbetering. (3) Zij dringen ook aan op de ondersteuning en aanmoediging van de ijverige onvermoeide, vruchtbare, stille arbeid ,,van de Brave Zendelingsbroederen der Moravische Broeder Uniteit", die als werkzame en nuttige mensen de hoogste lof verdienen, daar zij de Negerslaaf niet alleen tot godvruchtige Christen, maar ook tot een ijverig en zedelijk mens, en tot een werkzaam en nuttig lid der maatschappij vormen.

Op dit rapport volgde een begeleidende opmerking aan de minister, waarbij gouverneur VAILLANT, anders dan zijn collega te Curaçao, het request gedeeltelijk steunde.

Bossers doet het in zijn geschriften voorkomen alsof de gouverneur het volkomen eens was met WENNEKERS, maar in feite acht VAILLANT slechts het kerkelijk huwelijk gewenst, en dan nog alleen voor stadsslaven, terwijl hij ook geen verbod wenst van separate verkoop. $Z$ ijn steun is dus zeer miniem, want hij vervalt in dezelfde tegenspraak als de commissie; beiden achten een christelijk leven mogelijk zonder huwelijksband voor samenlevenden.

VAILLANT oordeelt dat een kerkelijk huwelijk voor plantageslaven, alhoewel gewenst, toch ondoenlijk is vanwege de verre afstanden, de slechte verkeersverbindingen, het gebrekkig onderwijs, en omwille van de aanleiding tot werkverzuim. Veel slaven, zo zegt hij, zijn Christen. In Paramaribo bestaan de dagelijks toenemende Moravische en R. Katholieke gemeenten merendeels uit slaven en vrije kleurlingen. Ook 
worden in de Hervormde Gemeente bij iedere Avondmaalstijd slaven aangenomen. Deze stadsslaven staan altijd ter beschikking van de eigenaar, ook al zouden de echtgenoten bij elkaar wonen. Voor hen zou het gouvernement wel kerkelijk formulieren, plechtigheden en toespraken kunnen toestaan, mits de eigenaar schriftelijk bewijs van toelating tot het huwelijk aan de geestelijke heeft overlegd.

Het antwoord en advies van VAILLANT handelt daarna nog over het beschaven van plantageslaven door blanken. Het zou goed zijn indien ook dit gedeelte, tegelijk met de volledige teksten van alle andere rapporten, gepubliceerd werd, ten behoeve van een nauwkeurige studie van deze Surinaamse periode; vooral het laatste rapport, na het advies van Vaillant, nl. dat van de Commissie voor de Zaken der Protestantse Kerken in Nederlands Oost en West Indië te 's-Gravenhage, moet meer bekend worden. Dit verscheen eerst vier jaren na Stöppels request (drie jaren na zijn dood) en twee jaren na dat van WENNEKERS, op 22 Mei 1821.

Het slotrapport der Commissie voor de Zaken der Protestantse Kerken werd gericht aan de Staatsraad, Directeur Generaal voor de Zaken der Hervormde Kerk. Dahlaus (p. 415) vat het aldus samen: (1) De klachten van de overleden pastoor van Curaçao, J. STÖPPEL, ondersteund door de pastoor van Suriname, behoeven geen gedeelte onzer overweging uit te maken. (2) De Katholieke priesters schijnen ijveriger, harder te werken, en meer personeel te hebben. Daarom wordt aangeraden om de vervallen Protestantse Zending te steunen door alle faciliteiten. (3) Het huwelijk der slaven is onmogelijk wegens hun wulpse hartstochten en om de eigendomsrechten der meesters niet te schaden.

Over het resultaat van al die rapporten, uiteindelijk ook van de requesten, worden door DaHLAus en Bossers geen officiële berichten vermeld.

Op Curaçao bleef het huwelijk in elk opzicht officieel verboden. Officieus schijnt er zo iets als een verlof bestaan te hebben om in stilte, of in het particuliere, bij wijze van onofficieel kerkelijk getuige te trouwen. Mgr. Niewindt schrijft echter in 1828, 1834 en 1848 nog om verlof tot officieel kerkelijk huwelijk. - Van het bestaan in Suriname van iets als de Curaçaose "matrimonia clandestina valida”, waardoor op dit eiland veel slaven in staat gesteld werden met vrije vrouwen te huwen (het omgekeerde kwam ook voor), is uit de Surinaamse missieliteratuur en haar bronnen niets gebleken.

Voor wat Suriname betreft besluit Bossers (Chron. p. 102) de tekst van het request met deze woorden: ,Dit verzoekschrift, ofschoon door den gouverneur ondersteund, bekwam geen gunstige beschikking. Van de zijde des bestuurs werd niets anders gedaan om in de rechtmatige bezwaren van den gouverneur en den pastoor te voorzien, dan dat het kerkelijk huwelijk, afgescheiden van het burgerlijk niet meer verboden werd." In zijn, voor BossErs uitgegeven Beknopte geschiedenis, heeft WulfiNGH (p. 131) alleen vermeld dat het kerkelijk huwelijk werd toegestaan. Meer kon de Prefect niet verkrijgen. - Of het bestuur nu 
de regering in Den Haag is, of het gouvernement te Paramaribo, en uit welke bron dit geput is, blijkt nergens, terwijl er ook in het archief van het Vicariaat te Paramaribo geen stuk van bestaat. Het schijnt dus een oogluikend toegestane practijk geweest te zijn.

Men kan nu echter terecht vragen of alles dan niet bij het oude was gebleven, en of STÖPPEL, en vooral WENNEKERS dan niet op de hoogte waren van deze oogluikend toegestane practijken. Immers, in 1782 waren er al kerkelijk getrouwde Herrnhutter stadsslaven, en in 1833 was er sprake van een getrouwde, separaat verkochte Coronieslaaf (STEINBERG, p. 89 en 92). Het kerkelijk huwelijk was dus eerder toegestaan dan het jaar 1850, toen bij de Evangelische Broedergemeente officieel het zogenaamd Verbond werd ingevoerd, dat al veel eerder oogluikend in zwang was $\left.^{1}\right)$.

Mijns inziens hebben de requesten van beide priesters echter wel degelijk belangrijke gevolgen gehad. Door al de rapporten en aanmaningen tot hernieuwde Protestantse Zending zijn zij aanleiding geweest tot oprichting van de Maatschappij tot bevordering van het godsdienstig onderwijs onder slavenbevolking, te Paramaribo in 1828, en in Den Haag in 1829, waarna de grote opbloei, althans de snelle groei van het aantal leden der slavenkerk begint.

Het waren vooral leden van de Loge, die het initiatief tot de oprichting van deze Surinaamse (in Nederland genoemd Haagse) Maatschappij namen.

De stoot der beide requesten werkte overigens op het terrein van het huwelijk slechts langzaam door. De commissies zagen duidelijk de verbondenheid van geloof, godsdienst, Evangelie met vrijheid en emancipatie; maar onduidelijk bleef voor hen, dat er zonder huwelijk geen geloofsleven kon bestaan voor de samenlevenden, dus geen waar Christendom. Toch wilden zij Christendom. De noodzakelijkheid van een emancipatie deed hen echter het huwelijk afwijzen - en daarmede zijn zij oorzaak geweest van langdurige inwendige moeilijkheden voor de kerkelijke gemeenten, van een schijnchristendom, en van een al te gemakkelijk gemaakte overgang tot het doopsel.

Behoud van de slavernij stond voorop in een door de tijdsomstandigheden en verarming beknelde kolonie. Dit is, tegelijk met de vrijzinnige geest der Loge, waarvan vele notabelen lid waren, een belangrijke oorzaak van de belemmering der christianisering. Maar het zou historisch onjuist zijn, en daardoor onrechtvaardig, om naast deze twee belangrijke

1) Uit SchneIder's werk, Foto, kan men afleiden, dat voor de Evangelische Broedergemeente het onderscheid tussen kerkelijk huwelijk en verbond gelegen was in het al of niet gebruik maken van kerkelijk ceremonieel. De Katholieke Kerk kende geen verbond, omdat de trouwbeloften, uitgesproken voor een priester, zonder ceremonieel en buiten het kerkgebouw, toch als wettig kerkelijk huwelijk golden. 
oorzaken, de hoofdfactor uit het oog te verliezen, nl. de Afrikaanse landbouwerscultuur van matriarchaat en avunculaat, waarin de Negerslaven geestelijk leefden. Volgens deze geesteshouding, nog versterkt door de Surinaamse omstandigheden, kende de Afrikaanse bevolking in Suriname geen Europees burgerlijk en ook geen algemeen Christelijk huwelijk. Twee levenshoudingen botsten in Suriname tegen elkaar, en dat nog wel in de meest ongunstige omstandigheden.

De economische of sociale argumenten van de rapporteurs der $\mathrm{Cu}$ raçaose, Surinaamse en Nederlandse commissies waren dan ook vanuit het standpunt der slavernij gegrond; de morele echter niet. Alleen waar zij spreken van afgodische denkbeelden raakten zij zijdelings de kern van de kwestie. Zijdelings, want de Neger erkende eigenlijk wel een oppermachtig Opperwezen, maar de conclusies omtrent zijn dienst waren anders dan de Christelijke. Verder is het heden toch wel een erkende waarheid, dat men niet, zoals deze rapporten doen, aan het negerras dat sexueel immorele karakter mag ",aanwrijven" dat destijds traditioneel opgeld deed, en tegenwoordig ook nog wel doet. Deze mening was gebaseerd op een, quasi exegetische, dwaling uit de tijd der koloniale slavernij, toen zelfs de Bijbel werd aangegrepen om de zogenaamde kinderen van Cham te doemen tot minderwaardige mensen, alleen bestemd voor slavernij.

STÖPPEL, WENNEKERS, in hun requesten, en later TANK, in zijn openbare brief, stonden op een hechtere grond van waarheid dan de rapporteurs. Hiermede is echter niet beweerd, dat zij als nieuwkomers direct de cultureel anthropologische moeilijkheden hebben ingezien, die door godsdienst-vrijheid of sociale vrijheid niet konden worden weggenomen. Zeker hebben zij niet voorzien, dat de Kerk ook na de slavernij nu reeds een eeuw lang met deze moeilijkheden worstelt en al strijdende ermede moet opgroeien. Onze gegevens over huidige vormen van samenleving zouden hen zeker verbazen, en de nog vrijwel onbestudeerde problemen op dit terrein nog meer. Naast ongepubliceerde rapporten of studies in kerkelijke archieven is dit terrein slechts even betreden door STEINBERG (p. 170 en 211), Herskovits (p. 16 e.v.), Ferrier (p. 63 e.v.) en van Lier. De uitvoerigste beschouwing hierover leverde Schneider (p. 171 e.v., 199-250). Hij behandelt een tiental factoren van historische, sociaal-economische en psychologische aard als oorzaken, maar de matriarchaatsfactor wordt door hem niet genoemd, zelfs niet bij de Bosnegers. In Het Apostolisch Vicariaat (p. 14 e.v.) en in De Katholiek (14 en 21 Sept. 1952) moest dan ook erkend worden dat deze kwestie nog wacht op een nauwkeurige bestudering, welke echter niet zo gemakkelijk is als men misschien zou menen.

Wanneer de requesten van de beide priesters royaal en welwillend behandeld waren zouden enkele der genoemde moeilijkheden thans stellig niet meer in zo sterke mate overheersen. Want dan was er van het begin af geen halfslachtig Christendom gepresenteerd. Nu werd te plotseling de regering en de meesters gewezen op het onverbrekelijk verbonden zijn van geloof, godsdienst en Evangelie met vrijheid en emancipatie. Wilde men Christendom dan was vrijheid noodzakelijk. Deze dreiging van een 
abrupte emancipatie is de verklaring van de totaal afwijzende houding in de rapporten, en het lijkt dan ook geen wonder, dat zelfs het Koninklijk Besluit van 1832 - waarbij toelating van zendelingen op plantages, van godsdienstig en ander onderwijs aan slavenkinderen verplicht werd - niet te vinden is in de Gouvernementsbladen van Suriname. De zekerheid, dat de slavernij nog niet werd afgeschaft, werd voor de meesters een prikkel te meer om zelfs het aangeboden halfslachtige Christendom nog zoveel mogelijk te belemmeren. Ook toen konden wreedheden nog ongestraft worden bedreven en separate verkoop was, hoewel ogenschijnlijk volgens de wet verboden, tot in 1861 in feite toegestaan (STEinBerG, p. 91 en 95). Slechts één gunstige omstandigheid was er voor de christianisering, waarop pas in 1856 bij Surinaamse gouvernementele verordening werd aangedrongen (Gouvernementsbladen, 30 Aug. 1856), namelijk het absolutistisch regiem der Regeringsreglementen, waarbij aan de gouverneur de beslissing in handen werd gegeven. Want als het weldadig werk van zendelingen en priesters alleen van de slaveneigenaars en van hun vertegenwoordigers in het Hof van Policie of Raden had moeten afhangen, dan zou de Kerk zich misschien pas in 1863 hebben kunnen vestigen.

\section{BRONNEN}

Abbenhuis, fr. M. F.: Het Apostolisch Vicariaat van Suriname. Koloniaal Missietijdschrift, Uitgave v.d. Indische Missievereniging, $1934-1938$.

Aвbenhuis, fr. M. F.: Het Apostolisch Vicariaat van Suriname. Paramaribo, 1942.

Abbenhuis, fr. M. F.: Honderd jaar Vicariaat 1852-1952. De Katholiek, Zondagsblad voor het Vicariaat van Suriname, Jubileumnummer, 5o, Sept. 1952,38 p. $2-4,3$ portretten (onderschrift 1e afb. moet zijn: Mgr J. Grooff, Apost. Visitator van Suriname).

Bossers C. ss. R., A.: Chronica missionis Surinamensis, 1683-1884. Manuscript, Pastorie Gravenstraat, Paramaribo, 361 pp. folio.

Bossers C.ss. R., A.: Beknopte geschiedenis der Katholieke Missie in Suriname. Bewerking der Chronica door K. Wulfingh C.ss. R., Gulpen, 1884.

Dahlaus O.P., S. J. M. : Een levensschets. Mgr. M. J. Niewindt. 1924.

Encyclopaedie van Nederlandsch West-Indiē. 's-Gravenhage, 1914-1917.

FERrier, J. H. E.: De Surinaamse samenleving als sociaal paedagogische opgave. 's-Gravenhage, 1950.

Godsdienstvriend, De, Tijdschrift voor Roomsch Catholyken. Amsterdam, 1818-1869. 
Gouvernementsbladen van de Kolonie Suriname. I8I6-1866. H. Nygh, Rotterdam, 1856 e.v.

Herskovits, M. J. \& Herskovits, F. S.: Suriname Folk-lore. New York, 1936.

Katholieke Encyclopaedie, De, Amsterdam, 1948 e.a.

Lier, Rudolf vaN: Samenleving in een grensgebied. 's-Gravenhage, 1949.

Lier, Rudolf van: De sociale wetenschappen van de Neger in Amerika. Bijdragen tot de Taal-, Land-en Volkenkunde, Jubileumnummer, 195 .

Loos, J. C. VAN DER: Vaderlandse Kerkgeschiedenis. Deel IV. Amsterdam, 1950.

Schneider, H. G.: Foto. Nymegen, 1893.

Staehelin, Ep. Un. fr., F.: Die Mission der Brüdergemeine in Suriname und Berbice im achtzehnten Jahrhundert. Herrnhut (I 1913, II 1914).

Steinberg, H. S.: Ons Suriname. 's-Gravenhage (1935?).

Wolbers, J.: Geschiedenis van Suriname. Amsterdam, 1861.

\section{S U M M A R Y}

The PETITIONS OF FATHER StÖPPEL AND PREFEct WENNEKERS IN 1816 AND 1817

The study of ecclesiastical sources concerning the petitions of J. StöPpel O.F.M. and Prefect P. Wennekers, in favour of the christianizing of Slaves, gives a better historical insight into the period when emancipation was still in its preparatory stage.

J. STÖPpEL addressed a petition in spite of the disapproval of his pastor primarius PIrovano and of the opposition and threat of suspension by the Governor of Curaçao. His petition was presented by J. Cramer, the chief priest of Holland, Zealand and West-Friesland, to KING William I. The immediate result was the renewed settlement of the Roman Catholic Mission in Surinam. In Curaçao the petition was in its whole rejected. That STöPPEL was fundamentally right, however, appeared from a similar action of Mgr. J. NiEwind from 1824 till 1860 in favour of the slaves.

In 1818 Prefect $P$. Wennekers started publishing reports from Surinam in the Dutch Roman Catholic monthly De Godsdienstvriend (The Friend of Religion). In these reports the Dutch Catholics were urged to a united action in favour of the Mission and the slaves.

WENNEKERS' request for education, baptism, marriage and a free married-life through the prohibition of the separate sale of members of one family was based on international and national statutory rights of the free exercise of religion, which rights were violated in every respect by slave-owners in Surinam.

In support of his argument he pointed out the benefit of religion for a well-ordered industrious slave-population. As a consequence of

West-Indische Gids XXXIV 
these two petitions the Minister issued a questionnaire which was submitted by the Governors of Curaçao and Suriname to a committee composed of the members of the Court of Police and a clergyman.

Both committees rejected the idea of civil and especially religious marriage as well as the implicit prohibition of separate sale of members of one family. Their reasons were of a juridical, economic and psychological nature. They were of opinion that allowing slaves to marry would practically be emancipation.

The Surinam Committee thought it impossible to instil in the minds of the negroes the notion of a Supreme Being, on account of their idolatrous conceptions and lascivious nature.

At the same time, however, they urgently advised to christianize the slaves through the medium of the Moravian Church and urged the marriage of free negroes and coloured people, large groups of whom threatened to develop into a community of unmarried people.

Both Governors added their recommendations to the answers of the respective committees. KIKKERT in Curaçao fully endorsed them; VAILLANT in Surinam differed from them in that he thought a religious marriage for town-slaves desirable.

The West Indian petitions, reports and recommendations were then summarised in a questionnaire, which was submitted by the „Staatsraad", Director of the Affairs of the Protestant Churches, to the Committee charged with the management of the Affairs of the Protestant Churches of the Dutch East and West Indies at The Hague.

This Committee replied that the complaints of the priests did not deserve any attention; that marriage between slaves was absolutely impossible on sexual-psychological and juridical grounds and that the Protestant Mission (which was in a state of decline) should be supported against the competition of the Roman Catholic Mission.

It is understandable that neither petition had any immediate and positive official result. Indirectly, however, they had. For, the existing custom, dating from the 18th century, of semi-official connivance at „silent" or clandestine religious marriage was allowed to continue; from that moment the Protestant Mission was greatly promoted and consequently developed in a marked and rapid manner.

The counter-recommendations contained in the reports, and the official prohibition emanating from a spirit of materialistic latitudinarian (watered-down or half-hearted) Christianity, greatly hampered religious life. The fact, however, that after a period of nearly a century of emancipation married life is still far from christian, and the number of illegitimate children of baptised persons still very large, indicates that still another factor has been at work besides those mentioned in the reports of the slave-period.

It is of no small importance to Church, State and Science that this matter, which so far has been greatly neglected, should be thoroughly studied. 